organization and inquiry into different aspects of Igala culture-agriculture, religion, political and legal institutions, as well as the internal development of the kingdom and its historical relations to neighbouring groups such as the Jukun, Edo, Yoruba, and Ibo.

Productivity and absenteeism among coal miners at Enugu, by Mr. W. M. L. Bispham, concerning especially changes in performance that may be associated with changes in working conditions and factors involved in a large increase in productivity which has occurred.

The transport movement of Nigerian export crops-a joint study by Mr. V. W. Hogg and Mr. H. P. White, based on analysis of the purchases of Marketing Boards.

Petty trading among the Ibo, an ethno-economic study by Dr. Margaret F. Katsin, with special reference to the means by which imported goods move to consumers in remote rural districts and the channels by which farmers' produce reaches the consumer; the different types of traders and middlemen and their place in the social structure are also being studied.

The social history of Lagos in the second half of the nineteenth century, by Mrs. Jean F. Kopytoff (née Herskovits), which is being revised for publication.

The relationships between the growth of Nigerian enterprises and legal forms of business organization, which is being completed by Mr. J. D. Nyhart.

Methods of treatment of psychiatric disturbances employed by Yoruba native practitioners, by Dr. R. Prince.

The pattern of import consumption and domestic production of agricultural commodities, which is being continued by Mr. W. D. C. Wright, in connexion with research for the estimation of future demands for imports and the adequacy of future supplies of local foodstuffs:

Industrialization in Nigeria and the Cameroons, by Professor F. A. Wells and Mr. W. A. Warmington, which has now been completed for publication.

\title{
Africans in East London (Cape Province)
}

The Institute of Social and Economic Research at Rhodes University, Grahamstown, is preparing three studies on African urbanization in East London under the editorship of its Director, Professor Philip Mayer. The first in the series, Townsmen or Tribesmen, by Philip Mayer, is being published for the Institute by the Oxford University Press (Cape Town); a further volume by Dr. Reader is in the press, and another by Dr. Pauw is in preparation.

\section{The African Studies Center, University of California, Los Angeles}

The African Studies Center of the University of California, Los Angeles, provides a framework for communication and collaboration among scholars from all the social sciences, education, linguistics, and the humanities; for developing and co-ordinating teaching programmes centred on Africa; and for furthering research on Africa in various fields of study. It works in close co-operation with the Near East Studies Center, under whose auspices instruction is offered in the history, cultures, and languages of the Islamic world.

It also offers a large number of courses, at graduate and undergraduate level, in the fields of Anthropology and Sociology, Economics, Education, Geography, History, Languages and Linguistics, and Political Science. The Center offers each year several fellowships, grants-in-aid, and research assistantships to graduate students.

Further information on the African Studies Center may be obtained from the Director (Professor James S. Coleman), African Studies Center, University of California, Los Angeles 24, California. 